\title{
Hypernatraemia-special problems with angiocardiography in total anomalous pulmonary venous drainage
}

\author{
Jane Somerville \\ From Institute of Cardiology and National Heart Hospital, London W.I
}

Two children with unobstructed total anomalous pulmonary venous drainage and hyperkinetic pulmonary hypertension deteriorated with pulmonary oedema and cerebral symptoms following angiocardiography using large amounts of contrast medium. One patient died. The dangers of this with resultant hypernatraemia are discussed.

Radiopaque medium such as Conray 420 used for angiocardiography contains approximately sodium I $\mathrm{mEq} / \mathrm{ml}$. In some forms of complex congenital heart disease, particularly those with a high pulmonary blood flow, large volumes of contrast medium must be injected if the anatomy is to be clearly shown on the angiocardiogram. When this is done, not only a quantity of sodium but also a hyperosmotic solution is added to an already overloaded circulation often associated with a failing heart even before the procedure is begun. This inevitably worsens the patient's condition, and unless the forward systemic flow and adequate renal perfusion is maintained there may be difficulties in getting rid of the sodium from the body.

Special circulatory problems are present in total anomalous pulmonary venous drainage, which may make the condition prone to serious complications after enthusiastic angiocardiography. The following two cases are reported to illustrate the dangers of obtaining a perfect display of the exact anatomy and in the hope of preventing these problems in the future.

\section{Case Reports}

Case I A 2-year-old boy, the product of a third normal pregnancy, was always slow to gain weight and fed with difficulty. From the age of 2 months he had recurrent respiratory infections, and congestive heart failure was documented at the age of 3 months and $I$ year, recurring frequently over the following year. Dr. M. Goldberg investigated him at Leicester Royal Infirmary and

Received 24 December 1969. confirmed his clinical diagnosis of total anomalous pulmonary venous drainage into the left innominate vein, but the presence of additional lesions such as ventricular septal defect and coarctation were suspected from the findings. $\mathrm{He}$ was transferred to the National Heart Hospital for surgical treatment. As the surgeon wished for exact delineation of pulmonary vein anatomy and other anomalies, reinvestigation was undertaken. At the time the child weighed $\mathrm{Ir} \cdot 3 \mathrm{~kg}$. and was in gross cardiac failure. The chest radiograph before investigation is shown (Fig. I), and the results of cardiac catheterization are summarized in the Table. General anaesthesia was given, the catheter was positioned in the common pulmonary vein, and $25 \mathrm{ml}$. Conray 420 was injected. The catheter was repositioned in what was thought to be the left ventricle but which was subsequently shown to be the right ventricle, and $20 \mathrm{ml}$. Conray 420 was given. A total of $52 \mathrm{ml}$. Conray 420 was given which included several test doses. The appearance of the lung fields on the screen suggested pulmonary oedema after the injection and $3 \mathrm{mg}$. frusemide was given intravenously.

Unfortunately, the child was extubated before consciousness was properly regained. He did not cry, breathing was irregular and gasping, and he became collapsed and cyanosed. He was reintubated and hand ventilated in the ward, which resulted in some improvement in his circulatory state but he was incontinent with widely dilated pupils. He passed some concentrated urine which was not measured. A chest radiograph confirmed pulmonary oedema and he was placed on a Bird ventilator and transferred to the recovery ward. At this stage, about an hour after the catheter procedure, it was decided that he was dehydrated and suffering from the effects of hypernatraemia precipitated by the large doses of sodium-containing contrast medium. The liver was impalpable, the eyeballs were soft, and the serum sodium was $156 \mathrm{mEq} / \mathrm{l}$. It was unlikely that this state 
was caused by the diuretic as there had not been a profound diuresis. The packed cell volume was 40, blood urea $55 \mathrm{mg}$., and serum K $4.4 \mathrm{mEq} / \mathrm{l}$. It was decided that a sodium diuresis was necessary but that fluid was also needed to produce it in view of the tissue dehydration. $80 \mathrm{ml}$. 5 per cent dextrose was given hourly and a further $2.5 \mathrm{mg}$. frusemide given after I hour. Urine was passed, and 3 hours later the pupils were smaller and reacting to light but he developed generalized twitching assumed to be epilepsy. The temperature was $39.8^{\circ} \mathrm{C}$. and he was curarized and given I5 mg. phenytoin sodium 6 hourly. The urine output appeared to be good and the serum sodium had fallen to $136 \mathrm{mEq} / 1$. The blood gases showed $\mathrm{Po}_{2} 75 \mathrm{~mm}$. and plasma bicarbonate $20 \mathrm{mEq}$. The fluid intake was reduced to $60 \mathrm{ml}$./hour of one-fifth dextrose/saline after 6 hours. By the following morning he was conscious, responding to his name, and reacting to pain, but there was still oedema in the lungs (Fig. I). Twenty-four hours after the collapse, his serum $K$ was 2.6 and he was still having fits, starting at this time in the right side and later involving the left side of the body. Tube feeds with $25 \mathrm{ml}$. half-strength milk and dextrose were started hourly and potassium was replaced intravenously. On the second day attempts were made to take him off the ventilator but he became restless with irregular respiration. He could not be safely extubated until later that day, 48 hours after the catheter. The pulmonary oedema had cleared on the chest radiograph. He remained in gross cardiac failure. Two weeks later anastomosis of the common pulmonary vein to the left atrium was performed successfully by Mr. Keith Ross. No fits have reoccurred and he now appears to be of normal intelligence and to have no neurological impairment.

Case 2 A 14-month-old boy was referred to The Hospital for Sick Children, Great Ormond Street, for surgical treatment for total anomalous pulmonary venous drainage into the left in- nominate vein. He was in gross cardiac failure on arrival from Spain. Chest radiograph showed the typical 'cottage loaf' heart shadow (Fig. 2), and the diagnosis was in little doubt. Before surgical treatment could be undertaken, it was required that the exact anatomy of the pulmonary vein anatomy be displayed and the presence of a persistent duct or other anomalies be excluded with certainty. When first seen the child was ill and breathless, weighing $6.8 \mathrm{~kg}$. He was transferred the following day to the National Heart Hospital for investigation, as the generator in The Sick Children's Hospital catheter room was being changed. He had deteriorated since the previous day and was more breathless and ashen, with a respiratory rate of $50-60 / \mathrm{min}$. He was given $0.8 \mathrm{ml}$. Peth. Co. as premedication and catheterized from the right saphenous vein after a fine Teflon tube had been put into the femoral artery for monitoring systemic arterial pressure. The results of catheterization are shown in the Table. After routine right heart catheterization, a general anaesthetic was given, and the child was intubated. The catheter was passed to the common pulmonary vein where the pressure was 25/16 $\mathrm{mm}$. $\mathrm{Hg}$ and $20 \mathrm{ml}$. Conray 420 was injected under pressure for biplane elema angiocardiography. As a specific request had been made that the anatomy of the left lower pulmonary veins be shown, a hand injection of $8 \mathrm{ml}$. medium was given at this site and a cine-angiocardiogram was recorded, which confirmed that these veins drained into the common trunk. The pulmonary venous pressure rose to $32 / 20 \mathrm{~mm}$. $\mathrm{Hg}$ after these procedures and the appearance of the lung fields on screening suggested that pulmonary oedema was added to plethora. In view of the request to exclude a persistent duct, the procedure was continued in spite of the deterioration. The catheter was changed as the small atrial septal defect could not be crossed with the first one. Several small test doses amounting to a total of ro $\mathrm{ml}$. Conray 280 were used before the catheter was safely positioned in the left

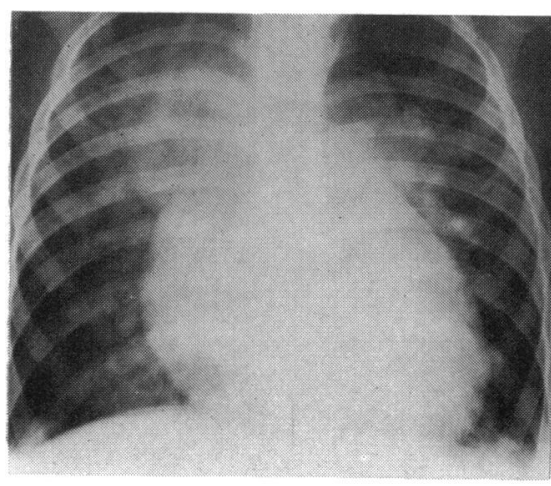

(a)

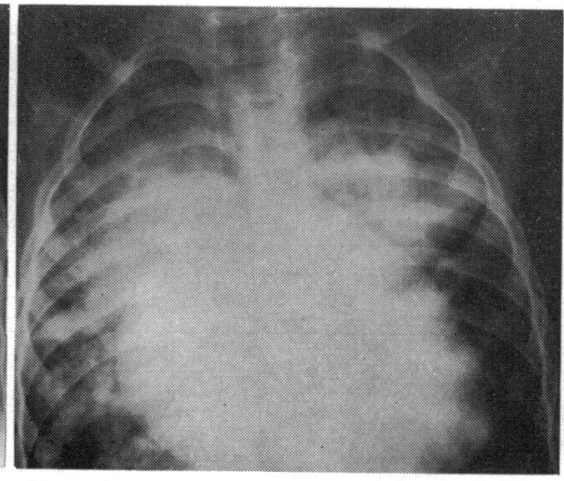

(b)

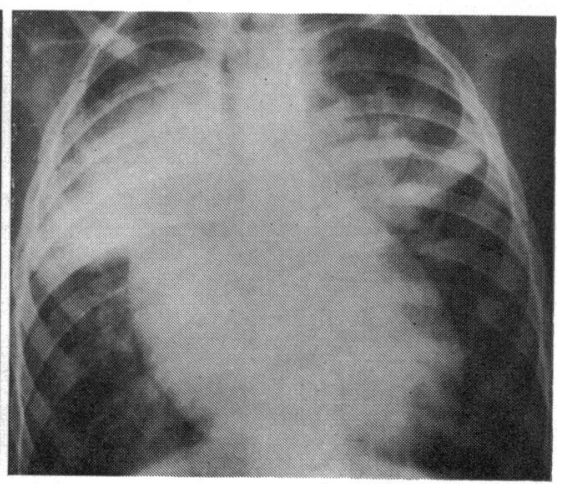

(c)

FIG. I Chest radiographs from Case I. (a) before catheterization; (b) immediately after catheterization showing obvious pulmonary oedema; (c) I hour later showing pulmonary oedema and smaller heart shadow. 


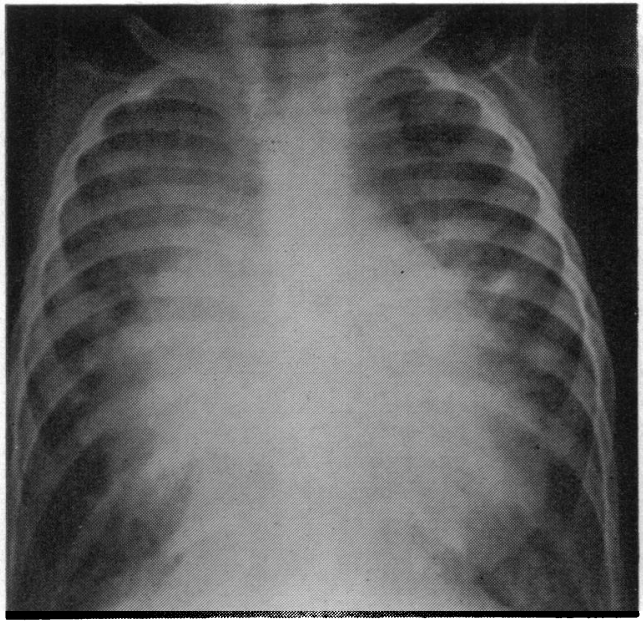

(a)

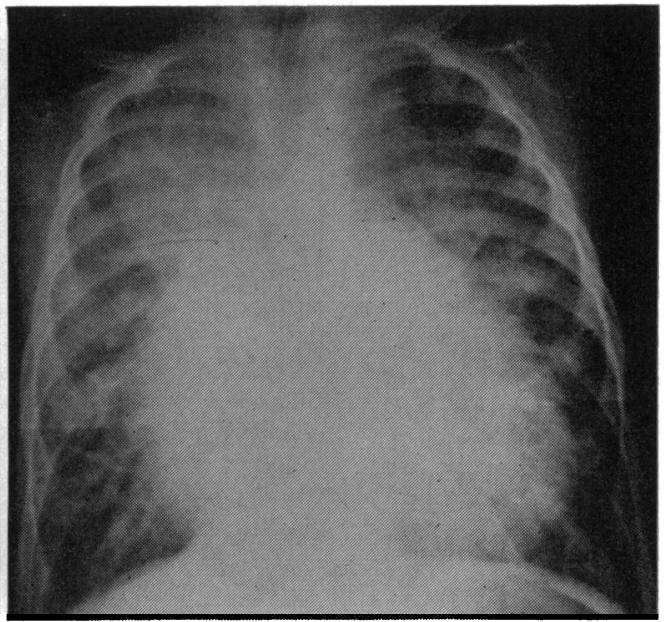

(b)

FIG. 2 Chest radiographs from Case 2. (a) day before catheterization;

(b) I hour after catheterization and angiocardiography.

ventricle. $8 \mathrm{ml}$. Conray 420 was rapidly injected and a biplane elema angiocardiogram was recorded. The arterial pressure fell to $50 \mathrm{~mm}$. $\mathrm{Hg}$ and the child looked ill. The blood loss of about $25 \mathrm{ml}$. was slowly replaced with $50 \mathrm{ml}$. crossmatched blood through the catheter which was then removed. An 'intracath' was left in the inferior vena cava as trouble was expected and it was planned to proceed to corrective surgery quickly. Some spontaneous respiration was present so in spite of the previous experience in Case I he was extubated. However, it soon became clear that he was collapsed, gasping, and unconscious, requiring reintubation and positive pressure ventilation. The chest radiograph confirmed the presence of pulmonary oedema. $2 \mathrm{mg}$. intravenous frusemide was given and it was found at this time that his plasma Na was $148 \mathrm{mEq} / 1$. and he was

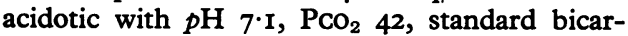
bonate 13 and $\mathrm{Po}_{2} 80 \mathrm{~mm}$. In spite of hypernatraemia Io $\mathrm{ml}$. sodium bicarbonate was given. He was returned to The Hospital for Sick Children in a low output unconscious state, and 4 hours later his temperature was $39 \cdot 4^{\circ} \mathrm{C}$, heart rate $180 / \mathrm{min}$., and plasma sodium $148 \mathrm{mEq} / \mathrm{l}$., potassium $5.3 \mathrm{mEq} / \mathrm{l}$., and blood urea $76 \mathrm{mg}$./ I00 $\mathrm{ml}$. He had status epilepticus with generalized twitching and three-quarters dilated pupils. Intravenous methohexitone was given, so that a satisfactory electroencephalogram could be obtained. Dr. G. Pampiglione reported this as showing severe generalized abnormality with continuous discharges and no normal rhythmic activity.

He passed small quantities of urine and was given $5 \mathrm{ml}$./hour of 4.3 per cent dextrose saline, blood, and $200 \mathrm{mg}$. intravenous THAM, and the $p \mathrm{H}$ was 7.4 one hour later. At midnight a cardiac arrest occurred, he was quickly resuscitated but arrest recurred 2 hours later. Four hours later at 4 a.m. the sodium was $134 \mathrm{mEq} / \mathrm{l}$. and potassium was $6.9 \mathrm{mEq} / \mathrm{l}$., with a blood urea $129 \mathrm{mg}$. and plasma osmolarity of 338 millimoles; $4 \mathrm{mg}$. intravenous frusemide was given without any increase in the fluid intake which did not produce a diuresis, and 2 hours later the

TABLE Haemodynamic data before and after angiocardiography in Cases I and 2

\begin{tabular}{|c|c|c|c|c|c|c|c|c|c|c|c|}
\hline & \multicolumn{7}{|c|}{ Pressures (mm. $\mathrm{Hg}$ ) } & \multicolumn{4}{|c|}{ Oxygen saturation $(\%)$} \\
\hline & $\begin{array}{l}\text { Systemic } \\
\text { artery }\end{array}$ & $\begin{array}{l}\text { Pulm. } \\
\text { artery }\end{array}$ & $\begin{array}{l}\text { Rt. } \\
\text { ventricle }\end{array}$ & $\begin{array}{l}\text { Rt. } \\
\text { atrium }\end{array}$ & $\begin{array}{l}\text { Common } \\
\text { pulm. } \\
\text { vein }\end{array}$ & $\begin{array}{l}\text { Lt. } \\
\text { atrium }\end{array}$ & $\begin{array}{l}\text { Lt. } \\
\text { ventricle }\end{array}$ & $\begin{array}{l}\text { Systemic } \\
\text { artery }\end{array}$ & $\begin{array}{l}\text { Pulm. } \\
\text { artery }\end{array}$ & $\begin{array}{l}\text { Rt. } \\
\text { ventricle }\end{array}$ & $\begin{array}{l}\text { Superior } \\
\text { vena } \\
\text { cava }\end{array}$ \\
\hline $\begin{array}{c}\text { Case I } \\
\text { Before } \\
\text { After }\end{array}$ & & $65 / 20$ & $\begin{array}{l}80 / 0 \\
75 / 15\end{array}$ & $\begin{array}{l}A=7 \\
X=2\end{array}$ & $\begin{array}{l}20 / 10 \\
30 / 18\end{array}$ & & $85 / 0$ & $\begin{array}{l}87 \\
76\end{array}$ & 88 & 90 & 72 \\
\hline $\begin{array}{c}\text { Case } 2 \\
\text { Before } \\
\text { After }\end{array}$ & $\begin{array}{c}110 / 60 \\
60-70 / \\
40\end{array}$ & $\begin{array}{l}100 / 55 \\
-\end{array}$ & $\begin{array}{l}100 / 8 \\
90 / 18\end{array}$ & $\begin{array}{l}A=17 \\
X=7 \\
28 / 10\end{array}$ & $\begin{array}{l}24 / 18 \\
M .20 \\
36 / 24\end{array}$ & $\begin{array}{l}A=20 \\
-\end{array}$ & $\begin{array}{l}105 / 4 \\
70 / 7\end{array}$ & 80 & 89 & 85 & 79 \\
\hline
\end{tabular}


potassium was $7 \cdot 2 \mathrm{mEq} / \mathrm{l}$. Insulin was given, but a further cardiac arrest occurred. Electroencephalogram showed long periods of equipotential activity, and an occasional signal from the temporal electrodes; the tracing was continued until further cardiac arrest occurred and attempts at resuscitation were abandoned. No necropsy was performed.

\section{Discussion}

These two patients developed a similar severe clinical state after angiocardiography. Before investigation both were in right heart failure with pulmonary hypertension, and they deteriorated, with pulmonary oedema, impaired conscious level, and low cardiac output after the procedure. The pathogenesis of this state can be only postulated, as the haemodynamic and laboratory data are incomplete.

In both patients the pulmonary venous pressure rose after the injection of contrast medium, and pulmonary oedema was seen on the screen and clearly documented by chest radiography (Fig. I and 2): this would probably increase pulmonary vascular resistance and reduce systemic flow. The systemic arterial pressure certainly fell and remained low in both patients after angiocardiography and we only have indirect evidence of a change in pulmonary artery dynamics by the further increase of end-diastolic pressure in the right ventricle. The acidosis and low blood pressure reflected the poor cardiac output. It is interesting that in Case $I$ the heart shadow appeared to be smaller on the chest radiograph in comparison with other films taken at the time of apparent dehydration in spite of pulmonary oedema, and it is possible that this was related to a reduced circulating blood volume.

With profound reduction in systemic blood flow which occurs when the pulmonary venous pressure and pulmonary vascular resistance become further increased in total anomalous pulmonary venous drainage, renal perfusion must be affected. This adds a further problem for the body to rid itself of the added large load of intravenous sodium given in the Conray 420 which was at least $52 \mathrm{mEq}$ $\left(\mathrm{Na}^{+}\right)$in Case $\mathrm{I}$ weighing $11 \cdot 3 \mathrm{~kg}$., and $36 \mathrm{mEq}\left(\mathrm{Na}^{+}\right)$in Case 2 weighing $6.8 \mathrm{~kg}$. The hypernatraemic state may well have been aggravated by the giving of frusemide alone without fluid, though in neither patient was much of a diuresis produced. Unfortunately, no measurement of urine flow was made in the first critical hour after the frusemide injections. Conray 280 is now used for test doses as it does not contain sodium and it is less radiopaque but it is a hyperosmotic solution and could be responsible for further increasing plasma osmolarity. Unfortunately, no measurements of this were made in Case I but it was increased when measured later in Case 2. Plasma hyperosmolarity and hypernatraemia would combine in effect to draw out fluid from the brain and other tissues and could lead to cerebral shrinking in the presence of pulmonary oedema. Disturbance of the respiratory centre in such circumstances would inevitably lead to loss of control and maintenance of adequate respiration in the presence of pulmonary oedema and losing control of ventilation by extubation is wrong, as shown in both patients. As it may be difficult to predict if these events are likely to occur after an investigation in this type of case, particular care should be taken before the anaesthetist removes the endotracheal tube and supportive ventilation to ensure that there is no pulmonary oedema or hypernatraemia. After these two experiences, the author believes that positive pressurc ventilation should be continued in such a patient until the child is fully conscious and has no evidence of radiological pulmonary oedema or profound fall in cardiac output. The hypoxia associated with pulmonary oedema worsens with uncontrolled ventilation and rapidly causes further deterioration in the poor haemodynamic state.

Having maintained control of ventilation, the main problem is to get rid of the sodium and redistribute fluid in the body. In small children whose fluid intake may have been restricted before catheterization and whose fluid volumes are small, diuretics alone may contribute to the dehydration and not be effective in removing sodium. Thus, it is believed that fluid must be given as well as a diuretic so it can act as a vehicle for sodium excretion and help to restore normal osmolarity. This procedure worked well in Case I but only minute volumes of fluid were given to Case 2, and it is likely that there was no sodium diuresis which might have accounted for the continued cerebral deterioration. Generalized fits and changing neurological signs are known effects of hypernatraemia and rapidly changing cerebral cellular chemistry (Cooke, 1959).

The unstable cerebral state persisted after restoration of the normal intravascular chemistry and adequate hydration of the patient, and it is recommended that intubation and ventilation is continued until the patient is fully conscious and no longer having fits. It is known that when brain sodium concentration is altered equilibrium across cell membranes may not be complete for up to 62 hours 
(Finberg, Kiley, and Luttrell, I963) so that fits may continue. A fit which is a severe hypoxic effort test may lead to cardiac arrest in the patient with a diseased heart. It may not be possible to extubate the child if pulmonary oedema persists, and an operation may be required as soon as the cerebral state improves.

Another important addition to therapy is to replace potassium if a diuresis is produced. As is seen in Case I where no potassium was initially given, the potassium was reduced to dangerously low levels and it was fortunate that dysrhythmias did not occur. In Case 2 the potassium did not fall probably because no diuresis occurred. Indeed the high potassium was probably related to the acidotic 'sick cell' state and may have accounted for the recurrent cardiac arrests. The need for frequent electrolytic estimations in this state is obvious. It must be accepted that Case 2 may have been more ill than Case I, and may have died because of this, but perhaps the absence of fluid replacement to assist a diuresis may also have been important. It is easy to understand the reluctance to giving plenty of intravenous fluid in a patient with pulmonary oedema. It is possible that vascular damage secondary to hypernatraemia (Finberg and Harrison, 1955; Finberg, Luttrell, and Redd, 1957) may have caused the brain damage, but unfortunately permission for necropsy was refused.

The frequency of these serious problems after angiocardiography is difficult to assess as there is an understandable reluctance to report this type of disaster. Only one other patient with total anomalous pulmonary venous drainage was investigated in the National Heart Hospital during this 2-year period and there were no complications, but less contrast medium was given in an older patient and poorer quality pictures were obtained. It is accepted that excessive doses of contrast medium were given in these patients, but this was necessary to display the anatomy for surgical needs. In the writer's experience, pulmonary oedema has been seen after giving large injections of dye in such diseases as mitral valve disease complicating large septal defects and other lesions with hyperkinetic pulmonary hypertension as well as in simple left-sided obstructive lesions. In simple obstructive lesions the problem differs because less dye per kg. body weight is needed and the problem is mainly a mechanical one. Indeed any complex heart disease such as transposition of the great arteries or other combinations of abnormalities may require large doses of contrast medium to display the anatomy adequately, and a raised plasma sodium and serious dehydration may be found after investigation, particularly in infants. It is possible that some of the effects of giving a lot of contrast medium may be related to giving a hyperosmotic solution and not all due to hypernatraemia but this requires further investigation, particularly if a lot of test doses of Conray 280 are used as this does not contain sodium but is hyperosmotic. The basic haemodynamics of total anomalous pulmonary venous drainage would particularly encourage the syndrome described here and large quantities of contrast medium would usually be required for clear definition of the anatomy.

In view of the obvious hazard of 'perfect' investigation in this type of patient, which is possibly higher than has been thought, the justification for taking this risk must be questioned. It is accepted that these patients are always ill with a poor prognosis when they present, and that the surgical problems and risks are increased if the pre-operative diagnosis is incomplete. In spite of this there is clearly a risk from using large amounts of contrast medium which may be needed in the presence of torrential pulmonary blood flow. When a 'cottage loaf' is obvious on the chest radiograph and right heart catheterization confirms the diagnosis, it is probably better not to display the anatomical diagnosis perfectly and not risk these hazards. The complete diagnosis can be made at operation with less risk, but it is accepted that complications and risks of operation may be greater with incomplete diagnosis. Thus the decision to accept inadequate data in a patient for operation may be difficult. In the author's opinion it would have been better to have done less angiocardiography in both these patients. The tragedy of any patient with a surgically correctable lesion who dies as the result of pre-operative investigation is obvious. Injection of over $2 \mathrm{ml}$. $/ \mathrm{kg}$. of the most refined contrast medium must carry special risks which may be particular in total anomalous pulmonary venous drainage but also present with other lesions.

I am most grateful to Dr. Eunice Lockey for helpful comments and advice on electrolyte management and to Dr. Keith Jefferson for his help and interest.

\section{References}

Cooke, R. E. (1959). The effects of sodium on the central nervous system. Proceedings of the Institute of Medicine of Chicago, 22, 312. 
Finberg, L., and Harrison, H. E. (1955). Hypernatremia in infants. An evaluation of the clinical and biochemical findings accompanying this state. Pediatrics, 16, I.

, Kiley, J., and Luttrell, C. N. (1963). Mass accidental salt poisoning in infancy. A study of a hospital disaster. Fournal of the American Medical Association, 184, 187.

, Luttrell, C., and Redd, H. (1957). Functional, anatomical, and biochemical alterations of the brain resulting from experimental hypernatremic dehydration. American fournal of Diseases of Children, 94, 542 . 